\title{
As dimensões singular e coletiva em saúde e a integração de serviços de saúde mental e saúde do trabalhador: algumas iniciativas no SUS de Betim (MG) ${ }^{1}$
}

\author{
Manoel Deusdedit Júnior² \\ Pontifícia Universidade Católica de Minas Gerais (Belo Horizonte, MG, Brasil)
}

\begin{abstract}
O presente artigo parte da constatação da existência de uma distância entre os campos da Saúde Mental e da Saúde do Trabalhador e discute como as concepções teóricas que servem de fundamento à atuação dos profissionais ligados a esses campos repercutem na sua lógica de funcionamento. Discute, ainda, como esses aspectos têm dificultado a integração desses serviços para lidar com os problemas de saúde mental e trabalho que chegam aos dispositivos de saúde do município de Betim (MG). A partir de uma pesquisa envolvendo entrevistas com profissionais, participação nas reuniões de equipe e levantamento de dados documentais, foram identificadas algumas ações dos profissionais de um dos Centros de Referência em Saúde Mental e do Centro de Referência em Saúde do Trabalhador do município de Betim que podem representar avanços na integração entre esses serviços. Para tanto, propõe-se que a categoria "trabalho" seja considerada como um aspecto importante na superação da dicotomia entre singular e coletivo na saúde, por ser ela importante na compreensão de casos de adoecimento mental e também na condução do tratamento de usuários dos serviços de saúde.
\end{abstract}

Palavras-chave: Saúde mental e trabalho, Saúde do trabalhador, Saúde mental, SUS.

The singular and collective dimensions in health and the integration of Mental Health and Worker Health care services: a few SUS initiatives at Betim/MG, Brazil

The present paper has as its starting point the awareness of the existence of a gap between the Mental Health and Worker Health fields. It discusses the impact that the theoretical views which provide the basis for the practice of professionals in both fields have upon these care services' operational logic. The paper also examines how these aspects have hindered the integration between both fields of care for the purpose of dealing with the mental health and work problems that are faced by the health care units in Betim/MG, Brazil. From a research involving interviews with professionals, participation in staff meetings, and collection of documental data, some practices of professionals in one of the Reference Centers for Mental Health and in the Reference Center for Worker Health in Betim have been identified that may represent progress in the integration between these care services. For this purpose, we propose that the "work" category be considered as an important element in overcoming the dichotomy between singular and collective in health, since it is important for understanding cases of mental illness and also for conducting treatment on patients in the health care units.

Keywords: Mental Health and Work, Worker Health, Mental Health, SUS.

\section{Introdução}

A Saúde Mental e Trabalho se caracteriza por estar na fronteira entre dois campos, a Saúde 1 do Trabalhador e a Saúde Mental, tangenciando-os, mas nem por isso confundindo-se com eles. Nesse sentido, os problemas que ali se apresentam desafiam a cada um desses campos, tanto no que diz respeito a sua compreensão, quanto à forma de solucioná-los, já que, no interior de cada um deles, tomado isoladamente, esses problemas ainda não são devidamente tratados. Assim, se a Saúde do Trabalhador se configura como estando ligada à Saúde Coletiva, o que pode implicar em certa dificuldade em compreender o processo de singularização da doença, a Saúde Mental pode

1 O artigo é resultado da tese de doutoramento realizada no Programa de Pós-Graduação em Psicologia da Universidade Federal de Minas Gerais. Parte da pesquisa foi financiada pelo Fundo de Incentivo à Pesquisa (FIP) da Pontifícia Universidade Católica de Minas Gerais.

2 Doutor em Psicologia Social pela Universidade Federal de Minas Gerais. Professor Adjunto do Departamento de Psicologia da Pontifícia Universidade Católica de Minas Gerais. 
se deparar com uma dificuldade oposta, ao limitar-se aos casos individuais, negligenciando (ou minimizando) a dimensão coletiva do adoecimento.

A proposta, aqui, é trazer alguns elementos que caracterizam a distância existente entre os serviços de Saúde Mental e da Saúde do Trabalhador do município de Betim, em Minas Gerais, mas com vistas a discutir algumas iniciativas realizadas pelos profissionais ligados a esses serviços e que apontam na direção de uma integração entre os dispositivos relacionados a ambos os serviços. Tais iniciativas sinalizam, ainda, a necessária superação da dicotomia entre singular e coletivo presente em algumas perspectivas na saúde. Nesse sentido, a forma como a categoria trabalho é considerada pode servir como um aspecto importante, não só na compreensão da distância entre os serviços analisados, mas também na articulação entre eles. Nossas reflexões partem, portanto, da discussão sobre a maneira como a categoria "trabalho" é vista no interior das principais perspectivas teóricas que fundamentam as práticas em cada um dos campos considerados, Saúde do Trabalhador e Saúde Mental. Em seguida, assinalamos, a partir dos dados obtidos em pesquisa realizada no Sistema de Único de Saúde (SUS) de Betim, algumas ações que, no nosso entender, avançam na direção da articulação entre os dispositivos ligados aos serviços investigados em nossa pesquisa.

\section{Investigando a saúde mental e a saúde do trabalhador em Betim: questões metodológicas}

As discussões propostas a seguir são resultantes da pesquisa de doutoramento do autor do presente artigo. Os dados foram levantados no período de setembro de 2010 a novembro de 2013 e a pesquisa está registrada no Comitê de Ética em Pesquisa da Universidade Federal de Minas Gerais (UFMG), sob o número CAAE - 0296.0.203.000-11.

Em Betim, começamos a desenvolver a coleta de dados a partir da análise do trabalho da psicóloga do Centro de Referência em Saúde do Trabalhador (CEREST) desse município. É importante salientar que até março de 2010 esse dispositivo não possuía um serviço de psicologia, e quando a psicóloga foi ali lotada já havíamos feito contato com a gerente e demais funcionários do CEREST para apresentar a proposta de pesquisa. A ideia de se analisar o trabalho da psicóloga se deveu ao fato de ela ainda estar estruturando, à época, o serviço de psicologia dentro do CEREST. A metodologia de análise do trabalho tem seus fundamentos na Ergonomia Francesa e toma a atividade como ponto central de compreensão e intervenção nos espaços de trabalho. Assim, "ao se estudar as situações de trabalho, o foco do ergonomista vai em direção das atividades realizadas pelos trabalhadores" (Telles, 1995, p. 18). No nosso caso, a proposta foi analisar o trabalho da psicóloga na perspectiva da Ergonomia de Concepção. Diferentemente da chamada Ergonomia de Correção, a Ergonomia de Concepção "estabelece um protocolo de projetação, onde a necessidade de considerar os trabalhadores e a atividade real de trabalho deve estar presente desde as primeiras etapas do projeto" (Telles, 1995, p. 21). Com isso em mente, passamos a acompanhar a psicóloga, observando sua participação nas reuniões de equipe e entrevistando-a, a fim de compreender as demais atividades que ela realizava, mas das quais não podíamos participar por questões de sigilo profissional (como os atendimentos individuais e em grupo que ela começou a realizar no serviço). Nosso objetivo, nesse momento, foi o de identificar as dificuldades encontradas e as estratégias desenvolvidas pela psicóloga na implantação desse serviço.

Nossa participação nas reuniões de equipe não se limitou, contudo, a abordar apenas o trabalho da psicóloga, mas objetivou compreender o funcionamento do serviço como um todo. Assim, mesmo após a conclusão dessa análise da atividade, em janeiro de 2011, continuamos a participar das reuniões de equipe do CEREST de Betim, pois concluímos que essa experiência seria essencial para nos permitir uma melhor identificação de como se daria a inserção de ações 
de Saúde Mental e Trabalho no município em questão. Nessas reuniões, num primeiro momento, eram discutidos casos atendidos por cada profissional, que os selecionava por considerá-los de difícil solução; continuamente éramos convidados a tecer comentários sobre casos que envolviam o comprometimento da saúde mental dos trabalhadores. Posteriormente, outros assuntos relativos ao funcionamento do serviço eram abordados, como questões burocrático-administrativas, ações a serem desenvolvidas etc. Cerca de uma vez por mês, a segunda parte da reunião era destinada à formação dos profissionais. Cada um deles (ou um convidado) preparava um tema para ser discutido pela equipe, estratégia denominada de "Rodas de Conversa". Ao longo da pesquisa, participamos de 40 reuniões de equipe no CEREST e de 16 Rodas de Conversa.

Com vistas a contemplarmos aspectos ligados à Saúde Mental e Trabalho, passamos a participar, também, das reuniões de equipe de um dos Centros de Referência em Saúde Mental do município, o CERSAM Betim Central. Antes de definirmos por esse serviço, procedemos a entrevistas com os gerentes de vários dos dispositivos da Saúde Mental de Betim, como o próprio CERSAM Betim Central, o CERSAM Citrolândia, o Centro de Atenção Psicossocial Álcool e Drogas (CAPS AD) e o Centro de Convivência "Estação dos Sonhos", além da referência técnica em saúde mental de Betim.

Nessas visitas, éramos acompanhados pela psicóloga do CEREST, que aproveitava a ocasião para apresentar aos gerentes e funcionários desses dispositivos o próprio CEREST e o serviço que ela estava estruturando nesse centro; também aproveitávamos a ocasião para obter a ficha de acolhimento usada por esses serviços. Além disso, participamos de quatro reuniões gerais envolvendo os profissionais de todos os dispositivos da saúde mental do município.

A opção pelo CERSAM Betim Central como o dispositivo da saúde mental a ser contemplado pela pesquisa se deu por ser este o primeiro serviço da área a ser inaugurado na cidade e por ser o dispositivo que atende à maior parte da demanda da microrregião. Demos início à participação nas reuniões de equipe dessa unidade em fevereiro de 2012, totalizando 24 o número de reuniões, que envolviam discussão de casos e também de questões administrativas.

Paralelamente às participações nas reuniões, realizávamos entrevistas com alguns profissionais desses dois serviços. No caso do CERSAM Betim Central, entrevistamos, além do gerente, dois psicólogos, uma assistente social e uma enfermeira (todas essas entrevistas foram gravadas). O objetivo dessas entrevistas era conhecer a rotina de trabalho, fluxos de atendimentos, dificuldades encontradas no cotidiano, não só no desenvolvimento das atividades no interior da própria unidade, mas também na articulação com os demais serviços da rede de saúde, dentre outras particularidades. No CEREST, voltamos a entrevistar a psicóloga em fevereiro de 2013, com o propósito de que ela avaliasse o serviço por ela iniciado há três anos; também entrevistamos uma das fonoaudiólogas do serviço, responsável pelo banco de dados sobre as notificações de agravos à saúde, SINAN. Realizamos, também, duas entrevistas coletivas, uma em cada um desses serviços, envolvendo vários profissionais.

É importante assinalar que durante esse período fomos convidados a participar de algumas capacitações realizadas pela psicóloga do CEREST nos diversos serviços de saúde do município. O principal objetivo dessas capacitações era levar aos demais serviços informações sobre o CEREST e também discutir, com os profissionais desses serviços, questões relativas à Saúde Mental e Trabalho.

No segundo semestre de 2012 também foi incluído no levantamento de dados um estudo do banco de dados dos atendimentos realizados pela psicóloga do CEREST, o que foi sugerido pela própria psicóloga, já que ela mesma sentia a necessidade de compreender o "perfil" dos casos atendidos por ela. Também foi organizado um banco de dados dos prontuários dos casos atendidos pelo CERSAM Betim Central no serviço de permanência-dia. Essa proposta, além de constituir um levantamento prévio de informações necessárias à nossa pesquisa, mostrou-se útil ao próprio serviço, que não dispunha dessas informações sistematizadas em um banco eletrônico de dados. 
Concluímos nossa participação nas reuniões de equipe do CEREST em 26 de abril de 2013, embora tenhamos mantido o contato com alguns profissionais desse serviço. No CERSAM Betim Central, finalizamos nossas visitas em novembro de 2013.

Outro aspecto metodológico de fundamental importância em nossa pesquisa se refere aos estudos de casos clínicos. Por fugir à proposta do presente artigo, não nos debruçaremos sobre essa estratégia, cabendo apenas assinalar que foram estudados quatro casos, dois deles provenientes do CERSAM Betim Central e os outros dois do CEREST.

Quanto à análise dos dados, adotamos algumas categorias oferecidas por Chasin (2009) com dados da leitura da obra de Marx e Lukács. A primeira delas concerne ao que o autor denomina momento preponderante. Entendendo que, na análise marxiana, temos uma "concepção dos complexos reais em sua gênese, vigência e desenvolvimento como uma teia constelar de determinações, relações e interconexões multiformes" (Chasin, 2009, p. 133), cabe destacar nessa constelação a categoria que representa o momento de onde se deve partir para se compreender a realidade, categoria que tem prioridade ontológica sobre as demais, sendo essa definida, portanto, como o "momento preponderante". Dessa forma,

o momento preponderante tem por identidade a condição de elo tônico no complexo articulado das abstrações razoáveis, ou seja, é o outro nome da categoria estruturante do todo concreto, e por isso também da totalidade ideal, uma abstração razoável que se destaca, sobredeterminando as demais com seu peso ordenador específico (Chasin, 2009, p. 135).

No contexto da nossa pesquisa, consideramos os casos clínicos como o momento preponderante, ponto de partida para a compreensão dos fluxos de atendimento prestado aos usuários, dos problemas aí encontrados, bem como de algumas das estratégias pensadas para a sua solução. Entendemos que os casos clínicos têm prioridade ontológica em nossa investigação por representarem uma "totalidade" da qual se derivam os demais elementos, que podem ser entendidos como determinações reflexivas, uma segunda categoria descrita por Chasin (2009). As determinações reflexivas só podem ser pensadas na perspectiva da articulação, "quando o foco recai em pares ou conjuntos de categorias cuja conexão é indissociável, de tal modo que a apreensão efetiva de cada um de seus membros depende da apreensão recíproca dos outros" (Chasin, 2009, p. 135), mas sem que se perca de vista a especificidade de cada um desses membros (ou elementos). É nesse sentido que concebemos os fluxos de atendimento como determinações reflexivas, por serem decorrentes da análise feita de cada um dos casos. Configurou-se, assim, em nossa pesquisa, o par categorial "casos clínicos/fluxos de atendimento", em que percebemos uma mútua determinação, mas sem perder de vista a especificidade de cada um desses elementos e o momento preponderante ocupado pelo primeiro.

Assim sendo, o que buscamos fazer foi identificar, em cada um dos casos estudados, os elementos essenciais dos fluxos de atendimento que nos permitissem compreender a relação dos dispositivos de saúde envolvidos em cada um deles, destacando tanto os aspectos que facilitaram quanto aqueles que dificultaram a sua condução.

Os achados oferecidos pelos estudos de caso foram articulados como os demais dados obtidos por meio das reuniões, análise de documentos, entrevistas etc. A articulação desses dados entre si e com a literatura científica resultou na escrita deste trabalho. Como assinala Chasin (2009), a articulação aparece, portanto, como o "momento culminante da produção do 'concreto de pensamentos', hora conclusiva da investigação” (p. 130). É importante destacar que a articulação não obedece a critérios puramente lógicos, mas é guiada pela "dialética da própria coisa" (Chasin, 2009, p. 135), princípio que nos guiou desde a etapa da coleta de dados. 


\section{O problema da integração entre os serviços de saúde mental e saúde do trabalhador}

O levantamento de dados realizado nos permitiu constatar que um dos principais problemas encontrados no desenvolvimento dos dois serviços investigados, CERSAM e CEREST, diz respeito à falta de integração deles entre si e com o SUS como um todo. Vários são os fatores que podem explicar as dificuldades de articulação entre os serviços de Saúde Mental e aqueles ligados à Saúde do Trabalhador em Betim. Interessa-nos, aqui, destacar as perspectivas teóricas que servem de fundamento às práticas dos profissionais que ali atuam e, em decorrência disso, a lógica de funcionamento desses serviços.

Quanto ao primeiro aspecto, é possível constatar que a divergência teórica dos profissionais que atuam nos diversos serviços de saúde é um dos itens bastante enfatizados por aqueles que tentam compreender as dificuldades encontradas na rede de saúde para lidar com os problemas de saúde mental dos trabalhadores. A esse respeito, Bernardo e Garbin (2011), por exemplo, ao analisarem uma experiência em um município do interior paulista, destacam que, quando profissionais ligados à saúde mental e à saúde do trabalhador se dispuseram a discutir sobre as ideias ligadas à origem dos distúrbios mentais apresentados pelos usuários do Centro de Atenção Psicossocial do município, constataram que as diferentes concepções se evidenciaram:

Enquanto alguns profissionais do CAPS focavam os problemas de saúde mental no intrapsíquico e discutiam a atividade de trabalho como uma escolha pessoal, as profissionais da saúde do trabalhador apontavam os aspectos sociais, indicando o trabalho como um fator fundamental no diagnóstico e no encaminhamento (Bernardo \& Garbin, 2011, p. 111).

Assim, essas mesmas autoras constatam que parte dos problemas de integração entre a Saúde Mental e a Saúde do Trabalhador está na

formação dos profissionais de saúde mental - especialmente psiquiatras e psicólogos - que ainda é fortemente influenciada por vertentes individualizantes. A formação médica em psiquiatria, de um modo geral, preconiza terapêuticas medicamentosas como a solução para a maior parte dos problemas de saúde mental. Já no campo da psicologia, as teorias predominantes - entre as quais, a psicanálise se destaca - enfatizam os aspectos individuais e familiares como as principais causas do adoecimento e do sofrimento psíquico, indicando a psicoterapia como a forma primordial de tratamento (Bernardo \& Garbin, 2011, p. 106).

No caso de Betim, essa divergência teórica também se faz presente. No CERSAM Betim Central ouvimos várias vezes os entrevistados dizerem que se valem da abordagem psicanalítica para atuarem nesse serviço. Alguns afirmam, inclusive, que várias das supervisões que tiveram desde que iniciaram ali suas atividades foram dadas por psicanalistas.

Sendo, portanto, a psicanálise tão influente nos serviços de saúde mental em Minas Gerais, e não menosprezando as evidentes contribuições que ela trouxe ao campo da saúde mental, cabenos interrogar em que medida essa perspectiva permite um tratamento adequado das questões relativas às possíveis relações entre as experiências de trabalho e os problemas de saúde mental apresentados pelos usuários desses serviços.

No caso específico do CERSAM Betim Central, é fácil perceber que os profissionais que ali atuam reconhecem, a princípio, que o trabalho tem importante papel, sobretudo na manutenção do equilíbrio psíquico dos usuários que passam pelo serviço, sendo um importante "recurso" na condução de alguns casos. E mesmo com relação às formas de trabalho protegido, os profissionais 
desse serviço mostram-se bastante críticos quanto aos riscos de que isso se torne um dificultador na reinserção dos usuários do serviço ao impedir que eles possam se relacionar com outros profissionais ou empresas, reforçando a segregação. De maneira igualmente crítica é pensada a dificuldade que a sociedade tem de aceitar o usuário da Saúde Mental no mercado formal de trabalho. Assim, podemos perceber que esses profissionais não têm dificuldade em reconhecer que a atividade laboral pode trazer benefícios terapêuticos aos usuários da Saúde Mental.

Porém, quando a questão se refere ao lugar do trabalho no adoecimento mental, vemos que essa categoria deixa de figurar como um fator relevante, ou até tende a ser desconsiderada. A esse respeito, um dos profissionais do serviço afirmou que "a questão 'saúde mental e trabalho', na minha experiência, ela é pouco tocada no CERSAM, na Saúde Mental. A gente pouco interroga o usuário qual a importância que tem o trabalho pra ele" (psiquiatra CERSAM Betim Central).

Essa perspectiva pode ser percebida, também, a partir de um levantamento dos prontuários relativos aos pacientes mantidos em permanência-dia nesse serviço, quando constatamos que, de 101 (cento e um) prontuários pesquisados, apenas em 32 (trinta e dois) deles constam informações sobre a profissão dos usuários. Isso sugere a irrelevância desse dado para os profissionais que acolhem e conduzem os casos que chegam ao serviço. Apesar de o número de prontuários pesquisados por nós ser pouco significativo, esse achado é reforçado, por exemplo, por uma pesquisa feita por Lima (2004) em torno de um grande número de prontuários de pacientes pertencentes a clínicas e hospitais psiquiátricos de Barbacena. Com base nesse levantamento, a autora trouxe importantes reflexões sobre o lugar que o trabalho tem ocupado para muitos dos profissionais que atuam na Saúde Mental. Na primeira fase da pesquisa, ela informa que "dos 3972 prontuários analisados [foi possível] identificar as atividades profissionais de 1711 pacientes" (p. 148), o que corresponde a menos da metade do total de prontuários. Esse dado permitiu a Lima (2004) constatar que "o descaso notório de muitas correntes da psiquiatria e da psicologia em relação a esses fatores [psicossociais na gênese dos distúrbios mentais] já fala por si" (p. 157). Conforme enfatiza a autora, "isto ficou bem ilustrado ... pela enorme dificuldade em localizar nos prontuários as informações sobre as dimensões psicossociais do adoecimento, especialmente as que diziam respeito às atividades profissionais" (Lima, 2004, p. 157). E, mesmo diante dos relatos de muitos dos pacientes que estabeleciam relações entre seu adoecimento e o trabalho, o que a autora evidenciou é que "seus interlocutores (psiquiatras, psicólogos, assistentes sociais, terapeutas ocupacionais) teimavam em ignorar esses conteúdos, direcionando a entrevista para os temas que julgavam mais 'relevantes"” (p. 158). Diante disso, ela concluiu que "não fica difícil deduzir que esses profissionais já tinham uma hipótese explicativa a respeito do problema, na qual o trabalho não ocupava qualquer lugar" (Lima, 2004, p. 158).

O que esse aspecto permite inferir é que, "ao desconsiderar a vida laboral anterior de seus pacientes, as equipes de saúde mental também podem tratar problemas relacionados ao trabalho como se esses fossem exclusivamente de ordem intrapsíquica” (Bernardo \& Garbin, 2011, p. 109), numa perspectiva "individualizante".

Assim, ao nos depararmos com dificuldade semelhante na identificação das profissões dos usuários do CERSAM Betim Central a partir da análise dos prontuários, vemos que essa lógica continua presente nos serviços de Saúde Mental do município e parece se perpetuar.

Baseando-nos nessas discussões, observamos que o trabalho é visto, pelos profissionais que atuam nesse campo, apenas na sua positividade, sendo desconsiderada a sua dimensão negativa, que aponta para os efeitos deletérios que ele pode ter na saúde mental dos trabalhadores. Vale destacar que, no nosso entender, essa visão parcial e unilateral do trabalho na relação com a saúde mental é decorrente, em grande medida, do referencial teórico que sustenta as práticas desses profissionais, nesse caso, a psicanálise. 
Aqui, vale retomar algumas das reflexões propostas por Lima (2011) ao buscar identificar a noção de trabalho presente nos chamados "textos culturais" de Freud. Ao realizar essa investigação, a autora observa que "as insuficiências no tratamento dado a esse tema no pensamento freudiano permitem compreender, em grande medida, os problemas apontados pelos seus maiores críticos" (p. 2). Nesse sentido, causa estranheza à autora a quase ausência da categoria "trabalho" na psicanálise como um todo, e em especial nesses textos "onde era de se esperar um tratamento exaustivo do tema, uma vez que parece difícil se pensar a cultura e os processos civilizatórios sem se levar em conta essa categoria" (Lima, 2011, p. 3). Também Jacques (2007) constata isso, esclarecendo que "na obra freudiana são poucas as referências à categoria trabalho" (p. 113) e, em alguns casos, é referida como categoria de pouca relevância para se compreender os distúrbios mentais, como no texto Análise terminável e interminável, no qual "o trabalho é citado como um possível fator inespecífico e secundário na etiologia do transtorno psíquico" (Jacques, 2007, p. 113).

Conforme podemos depreender das análises feitas por Jacques (2007) e Lima (2011), a categoria trabalho é marginal na teoria psicanalítica e, mesmo quando Freud trata dela, deixa transparecer a imprecisão com a qual é apreendida no conjunto de sua obra.

Encontramos outra dimensão do problema nas discussões feitas acerca do nexo causal entre trabalho e adoecimento mental, polêmica levantada por Christophe Dejours (1987). Não por acaso, a base teórica sobre a qual esse teórico se sustenta é a psicanalítica. Nos dizeres de Lima (2003), Dejours nega "a existência de neuroses ou de psicoses do trabalho. Tais afecções, segundo ele, eram resultantes, em última instância, das estruturas de personalidade forjadas muito antes da inserção dos indivíduos no mundo produtivo" (Lima, 2003, p. 83). A partir daí, fica fácil compreender sua dificuldade, bem como a dos profissionais que trabalham nessa mesma perspectiva, em reconhecer o lugar do trabalho no adoecimento mental.

Esse pode ser entendido como mais um fator que dificulta a aproximação do CERSAM ao CEREST, posto que, para esse último, o trabalho é tido como um dos principais determinantes dos processos saúde-doença, o que, como vimos anteriormente, não condiz com a perspectiva comumente adotada pelos profissionais da Saúde Mental.

Os dados de que dispomos sobre a origem do CEREST Betim sugerem que esse serviço pauta suas ações na perspectiva da Saúde Pública, mais precisamente, da Saúde Coletiva, tendo como um de seus pilares

a compreensão e o compromisso com a atenção integral à saúde, que abrange o desenvolvimento de ações de promoção e proteção, vigilância e assistência, incluindo a reabilitação física e psicossocial, considerando o papel do trabalho na determinação do processo saúde-doença dos trabalhadores (Dias \& Silva, 2012, p. 13; grifos nossos).

Portanto, na base das ações promovidas pelo CEREST Betim encontra-se o trabalho, que aparece como um dos elementos fundamentais para se compreender os problemas de saúde enfrentados pelos usuários. O que percebemos é que, nesse serviço, é essa concepção que norteia suas práticas, a saber, aquela baseada na Medicina Social Latino Americana.

Nessa perspectiva, a discussão sobre a forma assumida pelo trabalho na ordem do capital é imprescindível para avançarmos na compreensão do adoecimento dos trabalhadores, o que significa dizer da importância de se estudar a especificidade do trabalho. Há uma necessidade, portanto, de se compreender em que contexto histórico ele se dá, quais os fatores que o determinam; enfim, quais as características próprias do trabalho ao qual estão submetidos os sujeitos.

Analisando a relação existente entre o trabalho e a saúde dos trabalhadores, Laurell e Noriega (1989) procuram definir as categorias essenciais para a compreensão dessa relação. Assim, 
partem da análise do processo de produção, tal como se verifica no capitalismo, assinalando as "suas duas facetas: o processo de valorização (de produção de mais-valia) e o processo de trabalho (de produção de bens)" (p. 105) como aspectos imprescindíveis para o estudo das formas de adoecimento relacionadas ao trabalho. Porque é a "lógica concreta do processo de valorização" (p. 105) que determinará as estratégias utilizadas pelo capital para efetivar a extração da maisvalia. "O processo de trabalho [por sua vez] é a materialização do processo de valorização e divisão do trabalho" (Laurell \& Noriega, 1989, p. 105) e é ele que surge, portanto, como "um dos elementos-chave para a compreensão dos determinantes da saúde do trabalhador, já que permite desentranhar de que forma se constitui o nexo biopsíquico dessa coletividade" (Laurell \& Noriega, 1989, p. 106). Se o trabalho determina de maneira importante a forma de inserção dos indivíduos no mundo, então a saúde será, em grande medida, determinada pela forma do processo de trabalho, o que aponta para a dimensão social do processo saúde-doença, noção cara à Saúde Coletiva.

No caso do CEREST Betim, vemos como a preocupação com a dimensão coletiva do adoecimento dos trabalhadores aparece, por exemplo, como forma de uma "recusa" inicial de alguns profissionais quanto à entrada de uma psicóloga no serviço. Conforme relato da própria psicóloga, a dificuldade de ser aceita ali se devia ao fato de que os profissionais consideravam que ela trabalharia atendendo apenas a casos individualmente, desconsiderando a dimensão social dos problemas de saúde apresentados pelos usuários.

Isso sugere certa dificuldade de se levar em devida consideração os aspectos singulares do adoecimento, posto que essa perspectiva adotada pelos profissionais do CEREST tende a enfatizar mais os aspectos coletivos do processo saúde-doença, tal como sugerem, por exemplo, Laurell e Noriega (1989), cujas contribuições não nos permitem compreender, por exemplo, o fato de que, submetidos às mesmas condições e organização do trabalho, alguns trabalhadores adoeçam e outros não. Para responder a essa questão, valemo-nos aqui das contribuições de Lima e Lima (1998) quando, ao realizar uma reflexão sobre o tema, concluem que, nas investigações próprias da Medicina Social, "a ênfase continua recaindo quase exclusivamente nos processos de saúdedoença coletiva, cuja compreensão teórica fica limitada aos processos sociais mais gerais" (p. 25).

De fato, constatamos, em Laurell e Noriega (1989), essa ênfase quase exclusiva nas dimensões sociais do processo saúde-doença, quando afirmam que, já que o "ambiente" em que vivemos é, antes de tudo, social, "decorre daí que os 'modos de andar a vida' sejam característicos das coletividades e não dos indivíduos". Dessa forma, concluem que os "casos individuais não podem ser a base sobre a qual se constrói uma concepção do nexo biopsíquico humano” (p. 102). E, um pouco mais adiante, são categóricos ao afirmar que "enquanto os estereótipos de adaptação caracterizam as coletividades humanas, é nestas que podemos estudar o nexo biopsíquico historicamente específico, e não nos indivíduos isolados" (Laurell \& Noriega, 1989, p. 103). Esses autores não deixam margem a dúvidas quando enfatizam que há a necessidade de

reforçar que os processos de desgaste caracterizam as coletividades humanas e não primariamente os indivíduos. Ou seja, se bem seja certo que o padrão de desgaste se expressa através dos indivíduos que integram a coletividade, não é senão nela que adquire pleno significado e visibilidade. Assim é porque não depende das características individuais biopsíquicas de cada um, mas das condições específicas através e ante as quais a coletividade se constitui como tal (Laurell \& Noriega, 1989, p. 117).

Mas, como advertem Lima e Lima (1998), "com isso, toda a diversidade das estratégias individuais e percepções pessoais ficam obscurecidas" (p. 25). Não se trata, aqui, de desconsiderar as valiosas contribuições de Laurell e Noriega (1989), sobretudo por trazerem um novo olhar para a compreensão do processo saúde/doença. Chamamos a atenção, apenas, para um limite que 
precisa ser superado se quisermos avançar na compreensão dos problemas de saúde, sobretudo a saúde mental: levar em consideração as singularidades dos indivíduos.

\section{Sobre a lógica de orientação do funcionamento dos serviços}

Outro aspecto para o qual achamos interessante chamar a atenção e que parece manter algum tipo de relação com a concepção teórica diz respeito à lógica que orienta os profissionais de cada um dos dispositivos analisados: enquanto no CERSAM os serviços parecem obedecer a uma lógica determinada pelos casos atendidos, no CEREST os serviços parecem se estruturar a partir da legislação (políticas, portarias, decretos) e a própria estrutura organizativa do município (secretaria, superintendência etc.). Não podemos negar que, de alguma forma, esse aspecto reforça a distância existente entre a Saúde Mental e a Saúde do Trabalhador, na medida em que parece haver duas formas de funcionamento que não dialogam entre si, por não haver uma "linguagem" comum a esses serviços.

Quando afirmamos que a diferença na lógica de funcionamento dos serviços parece manter algum tipo de relação com a concepção teórica, queremos dizer que as teorias que servem de base para cada um desses serviços têm influenciado diretamente na lógica que imprimem às suas ações. Ou seja, se no CERSAM observamos que sua origem se liga à reforma psiquiátrica e por ser a psicanálise uma das abordagens mais influentes nesse contexto, não é de se estranhar que o modelo de assistência aos casos em que se prioriza o atendimento individual seja o que mais vigora nesse serviço e que parece determinar a tônica do seu funcionamento.

Dessa forma, observamos que no CERSAM Betim Central os principais argumentos para justificar as ações e reivindicações por melhorias giram em torno dos casos atendidos, sendo a "clínica", ou mais precisamente o "cada caso", o critério primordial para se determinar todo o fluxo de funcionamento, e também a direção do tratamento a ser dado ao usuário, até mesmo quando os problemas de saúde extrapolam as questões relativas à saúde mental, envolvendo outros problemas de saúde.

Durante o período em que estivemos presentes no CERSAM Betim Central, ouvimos várias vezes os profissionais dizerem o quanto a "clínica" é primordial e a base sobre a qual deve se sustentar o serviço. Apesar de não podermos afirmar que a noção de clínica seja unívoca e precisa entre esses profissionais desse serviço, parece-nos que ela está sempre associada ao atendimento individual dos usuários.

Ao assinalarmos essa ênfase do CERSAM no atendimento individual prestado aos usuários do serviço, não queremos, evidentemente, dizer que ela é equivocada. Nossa intenção, ao chamarmos a atenção para esse aspecto, é apenas destacar o quanto essa forma de atendimento diverge, sobretudo quanto às bases teóricas, daquela praticada pelo CEREST, e o quanto isso pode nos ajudar na compreensão da dificuldade de articulação entre esses serviços.

Quanto a este último, vimos que suas ações se pautam em perspectivas distintas daquelas observadas no CERSAM Betim Central, com estratégias quase sempre referenciadas ao que prescrevem as leis, portarias etc. Nesse serviço, observamos que a legislação parece ser o principal instrumento utilizado pelos profissionais, não só para se fazer reconhecido no município, mas também para a própria organização do serviço.

No período em que participamos das reuniões do CEREST, observamos, com muita frequência, o esforço dos profissionais em entender o que a legislação estabelecia como diretrizes para funcionamento dos serviços dessa natureza. Uma das reuniões de equipe, por exemplo, foi integralmente destinada a discutir a "Política Nacional de Segurança e Saúde do Trabalhador" (PNSST) e o quanto essa política implicava a organização do serviço. 
No caso específico da psicologia, essa forma de pensar o funcionamento do serviço colocou algumas dificuldades iniciais, já que a não existência do cargo de psicólogo no CEREST Betim desde a sua fundação contribuiu para a falta de clareza na definição do papel desse profissional. Além disso, não são muitas as referências com que se pode contar, já que a atuação do psicólogo em CEREST é algo relativamente recente na profissão. A esse respeito, a própria psicóloga comenta que "agora aqui no CEREST tinha um complicador que nem o cargo existia, né?... Você está tendo que construir tudo isso, né?... a existência do serviço de psicologia no CEREST" (Psicóloga CEREST). Para tanto, a psicóloga se valeu, dentre outras referências, principalmente das mesmas diretrizes que servem de orientação ao modelo de funcionamento do serviço como um todo, o que pressupõe uma integração dos diversos dispositivos do SUS entre si.

Assim, observamos, por um lado, o quanto o CEREST se encontra, a princípio, bem mais afinado com a proposta de uma rede integrada, dando passos consistentes nessa direção, como é possível observar, por exemplo, a partir da realização de um projeto de "qualificação dos Agentes Comunitários de Saúde para a implementação de ações de Saúde do Trabalhador na Atenção Básica" (Silva, 2009, p. 18), cujo objetivo foi a "preparação dos profissionais da AB, especialmente, dos agentes, que possuem melhor acesso aos trabalhadores e às diferentes atividades produtivas desenvolvidas em seu território de atuação" (p. 18). Por outro lado, essa mesma estratégia de se pautar pela legislação parece trazer algumas dificuldades na efetivação de ações mais concretas que definam uma "identidade" própria ao serviço. Ao que parece, por serem relativamente recentes as leis que regulamentam e estabelecem as diretrizes para esse tipo de serviço, o CEREST Betim, ao tentar ajustar-se a essa legislação, fica constantemente em "estruturação", à mercê do que estabelecem as leis, portarias etc., sendo que estas nem sempre correspondem à realidade sobre a qual o serviço é chamado a atuar.

Evidentemente, também não queremos, com isso, apontar como um equívoco essa opção de se pautar pelas diretrizes estabelecidas pelas leis. O que queremos ressaltar é a dificuldade, no caso do CEREST Betim, de aliar a própria história do serviço ao que tem sido proposto pela legislação.

Assim, se considerarmos os dois dispositivos que vimos analisando ao longo de nossas reflexões, CERSAM Betim Central e CEREST, vemos que eles partem de lógicas distintas para se organizar, tanto interna quanto externamente, ao se articular entre si e com os demais dispositivos do SUS de Betim. Apesar de não termos razões para supor que essas duas lógicas de funcionamento dos serviços sejam incompatíveis entre si (aliás, tendemos a ver muito mais uma complementariedade do que propriamente incompatibilidade entre elas), o que podemos observar é que ainda falta uma efetiva integração que permita alcançar, por meio de ambas as lógicas, um objetivo comum: uma atenção à saúde dos usuários dos serviços que dê conta dos problemas apresentados por eles, incluindo os casos envolvendo problemas de saúde mental relacionados ao trabalho.

É possível que, além das próprias especificidades do caso de Betim, essa forma de organização dos serviços já exista, desde os níveis mais elevados da hierarquia da estrutura administrativa do país na determinação das políticas públicas, até ao seu gerenciamento. Assim, nessa estruturação, podemos observar os elementos que apontam para lógicas que reforçam a separação entre os dois campos aqui analisados. Nessa mesma direção, Bernardo e Garbin (2011), ao discutirem sobre a relação entre a Saúde Mental e Trabalho no Brasil, comentam que

o primeiro aspecto a ser destacado diz respeito ao gerenciamento dos serviços e das áreas programáticas. Deve-se lembrar de que, desde sua incorporação no sistema de saúde, tanto a Saúde Mental como a Saúde do Trabalhador tiveram coordenações distintas em todos os níveis do SUS (Ministério da Saúde e Secretarias Estaduais e Municipais de Saúde, especialmente de municípios de grande porte), estando ambas apartadas da gestão da atenção básica. Desse modo, as ações de cada uma dessas áreas se pautaram mais fortemente nas suas próprias necessidades e especificidades (p. 108). 
O que observamos, no caso de Betim, é que, de fato, o caminho percorrido pelos serviços de cada uma dessas áreas tem obedecido a lógicas distintas, o que dificulta a sua integração, sendo tal movimento análogo ao que pode ser observado, de um modo geral, no país como um todo.

\section{"Embriões" da articulação entre saúde mental e saúde do trabalhador}

Apesar de enfatizarmos anteriormente alguns dos fatores que têm dificultado a articulação entre os serviços da Saúde Mental e da Saúde do Trabalhador em Betim, se lançarmos um olhar para o próprio fazer dos profissionais desses serviços, é possível vislumbrar sinais de criação de uma rede de saúde mais integrada e articulada. Nossa intenção, aqui, é destacar alguns elementos presentes na organização dos processos de trabalho dos serviços investigados e algumas das práticas desenvolvidas por esses trabalhadores, as quais parecem apontar na direção da superação de um "fosso" entre Saúde Mental e Saúde do Trabalhador.

Analisemos, inicialmente, algumas das atividades realizadas pelos profissionais do CERSAM Betim Central e que parecem conter elementos que sinalizam possibilidades de articulação com os demais serviços de saúde.

Do que já foi exposto, é possível observar que a ênfase do trabalho realizado nesse dispositivo recai sobre os casos. Desse modo, um recurso que surge como fundamental na sua condução é o "projeto terapêutico" que é definido para cada paciente. Esse aspecto é tão essencial ao serviço, que, em reunião organizada pelo gerente para discutir o trabalho no CERSAM Betim Central, grande parte do tempo foi destinada exclusivamente para avaliar como o "projeto terapêutico" tem sido realizado pelos profissionais da unidade. Na ocasião, algumas das questões que orientaram as reflexões foram:

Como o CERSAM Betim Central tem realizado os projetos terapêuticos e quem tem se responsabilizado por eles? ... Quais os critérios e parâmetros para a construção dos projetos terapêuticos elaborados? ... Quais os fatores existentes no CERSAM Betim Central que facilitam a elaboração dos projetos terapêuticos? E quais fatores que dificultam? ... Com qual periodicidade os projetos terapêuticos são revisados? ... Quais os recursos necessários ao tratamento são utilizados (terapia, oficina, visitas domiciliares, acompanhamento terapêutico, atividades em instituições externas ao CERSAM, reuniões com familiares, etc.)? Há um roteiro para a elaboração do projeto terapêutico individual? Qual tem sido a função do técnico de referência no CERSAM Betim Central? O que a rede de Betim oferece para o pós alta? Quais as principais instituições acionadas e como são acionadas? (Leitura do roteiro de perguntas para discussão, feita por um dos psiquiatras do CERSAM Betim Central).

É possível identificar, nessas questões, como essa forma de estruturar o atendimento se apresenta como o meio através do qual pode ser pensada a articulação com os demais serviços presentes no município. Ou seja, como sugerem os dados, é a partir de cada caso atendido no serviço que os profissionais do CERSAM vão acionando os demais dispositivos do SUS, bem como outros que se fazem necessários à atenção prestada ao usuário. Como resultado disso, o serviço tem conseguido, mesmo que modestamente, se articular com outros pontos da rede de saúde e ampliar suas parcerias com outros tipos de serviços.

Há, ainda, outras iniciativas desenvolvidas no CERSAM Betim Central que possibilitam uma maior interação entre os profissionais desse dispositivo com aqueles ligados a outras unidades, favorecendo a articulação entre os diferentes serviços de saúde. A esse respeito, uma das profissionais do serviço assinalou, por exemplo, que, mesmo diante das dificuldades, tem havido um esforço, por parte da Saúde Mental, de retomar projetos nos quais essa articulação era contemplada. Dentre 
esses projetos, uma proposta de trabalho que tem sido implementada na rede de saúde do município consiste na divisão da equipe do CERSAM Betim Central em duplas, que se responsabilizam por acompanhar as ações desenvolvidas pelos trabalhadores da Atenção Básica.

Outra ação que apresenta grande potencial na articulação entre os dispositivos da rede de saúde como um todo é a Residência Multiprofissional em Saúde Mental, programa desenvolvido em parceria entre a PUC Minas e a Secretaria de Saúde do município, sendo um dos seus coordenadores e principal articulador um dos psiquiatras do CERSAM Betim Central. Pela proposta desse programa, os residentes (psiquiatras, assistentes sociais, psicólogos, terapeutas ocupacionais, enfermeiros) passam pelos vários serviços de saúde do município. A proposta do programa é formar os residentes já dentro da lógica da integralidade, sendo que a circulação pelos diversos dispositivos torna-se um meio de fazer com que esses profissionais conheçam a rede como um todo.

Em suma, consideramos que, no CERSAM Betim Central, há condições que podem favorecer o desenvolvimento de propostas de trabalho mais integradas aos demais dispositivos da rede de saúde, já que, nesse serviço, observamos uma lógica de funcionamento que propicia a inventividade.

No caso do CEREST, percebemos esses "embriões", especialmente no serviço de psicologia que foi ali implantado. Nosso interesse por esse serviço ocorreu, sobretudo, após constatarmos que as questões de saúde mental dos trabalhadores só começaram a ser devidamente tratadas de maneira mais sistemática, na Saúde do Trabalhador em Betim, a partir da chegada de uma psicóloga a esse serviço.

Uma breve análise da forma como se deu a inserção da psicologia nesse serviço nos permite compreender, portanto, como isso tem repercutido no interior desse dispositivo como um todo e como tem possibilitado a implementação de estratégias para a inserção de ações com foco na Saúde Mental e Trabalho na rede de saúde, de forma a permitir uma melhor articulação, sobretudo, entre a Saúde do Trabalhador e a Saúde Mental.

Quando do início do funcionamento do CEREST, a ausência de um profissional apto a lidar com as demandas de saúde mental dos trabalhadores fazia que aqueles que ali estavam tivessem que atender aos usuários, mas sem se sentirem qualificados para tal. Essa situação obrigava os profissionais a encaminharem os pacientes para algum dispositivo da rede onde pudesse haver algum outro profissional supostamente apto a lidar com esse tipo de demanda, ou mesmo para outros serviços que eram criados fora da rede SUS de Betim.

Com a entrada da psicóloga no serviço, uma das primeiras consequências foi com relação ao atendimento prestado aos usuários que ali chegavam, já que grande parte da demanda interna ao próprio CEREST pôde ser absorvida por ela, o que resolveu alguns dos problemas que a equipe tinha quanto aos encaminhamentos que eram feitos aos demais dispositivos.

É importante ressaltar que à época da entrada da psicóloga no CEREST, este já pautava suas ações pela Rede Nacional de Atenção Integral à Saúde do Trabalhador (RENAST), exigindo que o serviço de psicologia que ali seria implantado seguisse o princípio da articulação com os demais dispositivos do SUS, nesse caso, principalmente a Saúde Mental.

Conforme já assinalamos anteriormente, apesar de haver certa "resistência" inicial quanto à entrada de um psicólogo no serviço, devido ao receio de que este pudesse limitar suas ações a atendimentos individuais, a visão que muitos profissionais desse dispositivo tinham a respeito da relação entre trabalho e saúde mental, admitindo a possibilidade de adoecimento psíquico em função da atividade laboral, acabou por contribuir para uma maior aceitabilidade da psicologia dentro do CEREST. Aliou-se a isso a postura da própria psicóloga que chegou ao serviço, descrita pelos profissionais como sendo aberta ao diálogo e às propostas apresentadas por esse dispositivo, o que favoreceu não apenas a sua aceitação, mas também a criação de um serviço mais adequado 
às demandas que surgiam. Assim, se de um lado a falta de referências mais claras sobre a atuação desse tipo de profissional dentro dos CEREST representou uma dificuldade inicial, por outro lado essa mesma situação possibilitou a construção de um serviço mais condizente com as necessidades do próprio município.

Durante o período em que investigamos o CEREST, acompanhamos o desenvolvimento das ações realizadas por essa profissional com vistas não só a atender aos usuários que chegavam ao serviço, mas também aquelas voltadas à articulação com os demais serviços. Dentre essas ações, destacamos: o matriciamento, em que se busca organizar o fluxo de usuários/trabalhadores na rede de saúde substituindo a lógica de encaminhamentos, de tal forma que os profissionais da atenção primária possuam suporte técnico especializado que os torne aptos a atenderem aos usuários portadores de doenças ou vítimas de acidentes relacionados ao trabalho, mas que podem ser resolvidos na própria atenção primária; a referência e a contra-referência, que consistem em manter registros dos casos, identificando os profissionais e unidades que encaminham trabalhadores ao serviço, mas também, a partir daí, permitindo traçar estratégias de divulgação do próprio serviço, procurando contemplar aquelas unidades que menos encaminham usuários; no caso da contra-referência, sobretudo no que diz respeito à saúde mental, a psicóloga passou a se servir desse recurso como meio de divulgar, aos profissionais que the encaminhavam os casos, informações sobre questões relativas ao adoecimento mental dos trabalhadores. Assim, essas ações são usadas como estratégia de formação e capacitação dos profissionais da rede. No que se refere a aspectos ligados à Saúde do Trabalhador, essas estratégias se inserem no bojo das ações que visam desenvolver a cultura da centralidade do trabalho na rede SUS, numa tentativa de superar entraves encontrados na consideração do trabalho como elemento importante no processo saúde-doença.

Nesse sentido, o uso desses recursos condiz com as ideias defendidas por Sato, Lacaz e Bernardo (2006) ao discutirem sobre as possibilidades de atuação da psicologia no âmbito da saúde pública. Esses autores assinalam, a partir de algumas experiências em São Paulo, que

outro papel importante desempenhado pela equipe multiprofissional dos PSTs/CERESTs, em que a participação do psicólogo é relevante, é a formação de profissionais de saúde que atuam em unidades básicas de saúde, pronto-socorros e hospitais. O objetivo dessa atividade é facilitar o reconhecimento, por parte desses profissionais, de que o trabalho possa causar problemas de saúde, de modo a incluir essa visão na prática profissional. A inclusão de tal ótica é importante no sentido de fornecer elementos para o diagnóstico diferencial, particularmente relevante nos casos de saúde mental que possam ter origem no trabalho (p. 286).

Na avaliação da gerente do CEREST Betim, a forma como o serviço se organizou para lidar com os problemas de saúde mental e trabalho no município e região tem possibilitado avanços não apenas no interior do próprio centro, mas também na articulação com a rede SUS de Betim. Contudo, apesar de reconhecerem que houve esse desenvolvimento do serviço, possibilitando uma melhor compreensão das causas do adoecimento mental dos trabalhadores, alguns profissionais assinalam o quanto o serviço ainda precisa avançar no que se relaciona à solução dos problemas que surgem nessa área.

\section{Considerações finais}

Podemos considerar que, de um lado, tal como as ações dos profissionais da saúde mental sugerem, o trabalho pode auxiliar na condução do tratamento dos usuários desse serviço e, de outro 
lado, como apontam as ações dos profissionais do CEREST, o trabalho representa um elemento importante na compreensão do adoecimento dos trabalhadores que buscam esse serviço. Com isso, não há como ignorar que estamos diante da constatação de que o trabalho faz a "ponte" entre o indivíduo e o seu meio, seja determinando a possível melhora do seu quadro, seja influenciando no seu adoecimento. Dessa forma, se o enfoque da Saúde Mental é o singular - partindo dos "casos clínicos" - e o da Saúde do Trabalhador é o coletivo - em que se leva em consideração os determinantes sociais do adoecimento -, a integração desses dois dispositivos pode permitir um maior alcance na compreensão e tratamento dos problemas de saúde mental dos usuários, caso a categoria trabalho seja devidamente incorporada nessas práticas.

O que vale ressaltar, contudo, é que, para um maior alcance dessas propostas, acreditamos que uma ampliação das discussões em torno da psicopatologia do trabalho por parte dos profissionais da saúde mental poderia permitir uma mudança na visão quanto ao lugar do trabalho no adoecimento mental dos trabalhadores/usuários. Nesse sentido, há a necessidade de se voltar o olhar para a atividade laboral em toda a sua amplitude, considerando-a tanto em sua positividade como também nos seus aspectos negativos, em que se destacam elementos - como a exploração, a alienação, a intensificação, a pressão, entre outros - próprios às formas de trabalho estranhado. A incorporação dessa dimensão na visão que os profissionais da Saúde Mental têm acerca do trabalho poderia ampliar as possibilidades de compreensão e, quiçá, de intervenção nesse campo. É também nesse sentido que vemos como promissora a aproximação entre o CEREST e o CERSAM Betim Central.

Não devemos nos esquecer de que um esforço por parte dos profissionais do CEREST também se faz necessário, no sentido de incorporarem as reflexões sobre os aspectos singulares na determinação do processo saúde/doença. As investigações no campo da Saúde Mental e Trabalho nos permitem constatar que não é possível compreender o adoecimento, e nem tampouco a melhora dos pacientes, sem levar em consideração aspectos ligados à história de vida de cada um deles, o que reforça a importância dessa dimensão.

Essa reflexão nos coloca diante de outro aspecto para o qual queremos chamar a atenção: a possibilidade da integração dos dois dispositivos a partir de suas lógicas de funcionamento. Conforme vimos, o CERSAM Betim Central baseia suas ações na perspectiva dos casos singulares, ao passo que o CEREST tem, como princípio de suas ações, a Saúde Coletiva. Já tivemos a oportunidade de assinalar que não vemos motivos para considerar essas duas lógicas como sendo mutuamente excludentes. Entretanto, falta um elemento aglutinador que sirva de amálgama entre essas duas perspectivas. Vemos que o trabalho pode representar esse elemento se entendermos que, forçosamente, essa categoria é o elo, por excelência, entre o individual e o social. Por isso afirmamos que longe de serem excludentes, essas lógicas apontam para uma complementariedade entre si, desde que, evidentemente, as questões teóricas sejam tratadas de forma adequada.

Apesar de considerarmos que as ações dos profissionais dos serviços investigados avancem na direção de uma maior integração entre os dispositivos da saúde, convém admitir, no entanto, que, em Betim, muitas dessas iniciativas ainda são incipientes, sendo modestos os resultados obtidos, que, contudo, já mostram o quanto são promissoras na efetivação de uma rede de saúde capaz de lidar com os problemas de saúde mental apresentados pelos trabalhadores. E, apesar de algumas dessas ações ainda estarem baseadas na tentativa e no erro, observamos que nessa aproximação dos serviços alguns projetos começam a ser vislumbrados, como propostas de trabalho conjunto envolvendo, além desses dispositivos analisados, outros serviços do município, como o CAPS AD, por exemplo.

É evidente que há muitos desafios a serem superados no campo da saúde em Betim para que se consiga um funcionamento razoável da tão almejada "rede SUS". A nossa intenção, aqui, é ressaltar que, ainda assim, nas próprias ações dos profissionais da saúde em seu cotidiano, 
encontramos alguns "embriões" de uma rede de saúde integrada, com dispositivos articulados entre si.

\section{Referências}

Bernardo, M. H., \& Garbin, A. C. (2011). A atenção à saúde mental relacionada ao trabalho no SUS: desafios e possibilidades. Revista Brasileira de Saúde Ocupacional, 36(123), 103-117.

Chasin, J. (2009). Marx: estatuto ontológico e resolução metodológica. São Paulo: Boitempo.

Dejours, C. (1987). A loucura do trabalho: estudos de psicopatologia do trabalho. São Paulo: Oboré.

Dias, E. C., \& Silva, T, L. (2012) Desenvolvimento de conceitos e instrumentos facilitadores da inserção de ações de Saúde do Trabalhador na Atenção Primária de Saúde, no SUS. Relatório Técnico Final (agosto 2008 a dezembro 2012). Belo Horizonte: UFMG.

Jacques, M. G. C. (2007). O nexo causal em saúde/doença mental no trabalho: uma demanda para a psicologia. Psicologia छ Sociedade, 19(Ed Esp. 1), 112-119.

Laurell, A. C., \& Noriega, M. (1989). Processo de produção e saúde: trabalho e desgaste operário. São Paulo: HUCITEC.

Lima, M. E. A. (2003). A polêmica em torno do nexo causal entre distúrbio mental e trabalho. Psicologia em Revista, 10(14), 82-91.

Lima, M. E. A. (2004). A relação entre distúrbio mental e trabalho - evidências epidemiológicas recentes. In W. Codo (Org.), O trabalho enlouquece? Um encontro entre a clínica e o trabalho, v. 1 (pp. 139-160). Petrópolis: Vozes.

Lima, M. E. A. (2011). The role and the meaning of work in Freud's cultural writings. International Forum of Psychoanalysis, 1, 1-14.

Lima, F. P. A., \& Lima, M. E. A. (1998). Introdução geral. In M. E. A. Lima, J. N. G. Araújo \& F. P. A. Lima. LER: dimensões ergonômicas e psicossociais (pp. 11-29). Belo Horizonte: Health.

Sato, L., Lacaz, F. A. C., \& Bernardo, M. H. (2006). Psicologia e saúde do trabalhador: práticas e investigações na Saúde Pública de São Paulo. Estudos de Psicologia, 11(3), 281-288.

Silva, T. L. (2009). Contribuição ao processo da capacitação dos agentes comunitários de saúde para o desenvolvimento de ações de saúde do trabalhador (Dissertação de Mestrado em Saúde Pública e Meio Ambiente, Escola Nacional de Saúde Pública, Rio de Janeiro, Brasil).

Telles, A. L. C. (1995) A ergonomia na concepção e implantação de sistemas digitais de controle distribuído: algumas considerações a partir de um estudo de caso na fábrica carioca de catalisadores. (Dissertação de Mestrado, COPPE, Rio de Janeiro, Brasil).

\section{Endereço para correspondência}

madeusjunior@hotmail.com
Recebido em: 01/04/2015

Revisado em: 04/10/2015

Aprovado em: 24/11/2015 